\title{
ANALYSIS OF MECHANICAL PROPERTIES OF HYDROTHERMALLY CURED HIGH STRENGTH MATRIX FOR TEXTILE REINFORCED CONCRETE
}

\author{
Ondřej HolčapeK*, Filip Vogel, Petr Konvalinka \\ Czech Technical University in Prague, Faculty of Civil Engineering, Experimental Centre, Thákurova 7, 16629 \\ Prague 6, Czech Republic \\ * corresponding author: ondrej.holcapek@fsv.cvut.cz
}

\begin{abstract}
The main objective of this article is to describe the influence of hydrothermal curing conditions in an autoclave device (different pressure and temperature), which took place at various ages of a fresh mixture (cement matrix - CM, and fibre-reinforced cement matrix - FRCM), on textile reinforced concrete production. The positive influence of autoclaving has been evaluated through the results of physical and mechanical testing - compressive strength, flexural strength, bulk density and dynamic modulus of elasticity, which have been measured on specimens with the following dimensions: $40 \times 40 \times 160 \mathrm{~mm}^{3}$. In addition, it has been found that increasing the pressure and temperature resulted in higher values of measured characteristics. The results indicate that the most suitable surrounding conditions are $0.6 \mathrm{MPa}$, and $165^{\circ} \mathrm{C}$ at the age of 21 hours; the final compressive strength of cement matrix is $134.3 \mathrm{MPa}$ and its flexural strength is $25.9 \mathrm{MPa}$ (standard cured samples achieve $114.6 \mathrm{MPa}$ and $15.7 \mathrm{MPa}$ ). Hydrothermal curing is even more effective for cement matrix reinforced by steel fibres (for example, the compressive strength can reach $177.5 \mathrm{MPa}$, while laboratory-cured samples achieve a compressive strength of $108.5 \mathrm{MPa}$ ).
\end{abstract}

KEYWORDS: compressive strength; flexural strength; dynamic modulus; steel fibres; hydrothermal curing; boundary conditions.

\section{INTRODUCTION}

Current research activities in the field of material science and civil engineering focus on investigations into the properties of advanced materials' and their implementation into real practical use. In the context of sustainability and global efforts to minimize energy intensity, new types of cement composites and special curing conditions to help achieve higher mechanical properties and durability are investigated. This paper deals with an experimental analysis of the influence of hydrothermal curing on the mechanical properties of cement matrix for textile reinforced concrete. The aim of this study is to quantify the mechanical properties of textile reinforced concrete cement matrix autoclaved under various boundary conditions (pressure in autoclave vessel and age of concrete). Hydrothermal curing took place at various ages after the first contact water of with cement (from 12 to 24 hours). Two types of concrete were used (cement matrix and fibre-reinforced cement matrix).

The material presented in this research was originally developed at the Experimental Centre, Faculty of Civil Engineering, CTU in Prague, for textile reinforced concrete production in general. Taking into account the international political situation and terrorist risks we can find its application for protective façade panes or slabs production. Projectile impact on slabs made from this composite (reinforced by various types of textiles and in some case in combination with steel fibres), as well as their response to dynamic load, have been experimentally investigated. Textile reinforced concrete (TRC) is a new type of advanced composite material with successful practical use in real constructions. The philosophy of TRC combines the advantages of cement matrix (high-performance concrete - HPC or ultra-high-performance concrete UHPC) and the tensile characteristics of textile, usually made from high-strength material (glass, carbon, basalt) [1]. The typical compressive strength of cement matrix lies in the range from 70 to $130 \mathrm{MPa}$. This material finds its application in façade panel production, strengthening of existing reinforced concrete load bearing elements, elements for footbridge manufacture [2], etc. Several elements of the structure belong to the category of prefabricates, where the time development of mechanical properties determines the removal from formwork and the economic efficiency of the production. The possibility of accelerating the increase of mechanical properties becomes more relevant; therefore the process of hydrothermal curing in an autoclave device becomes more important. The effect of hydrothermal curing on the mechanical properties of $\mathrm{CM}$ and FRCM is presented in this article.

Several works of research deal with the issue of the effect of the curing conditions of concrete and high-performance cement composites on final mechanical properties and their development in time. The final properties depend on the composition of the mixture (use of active admixtures, type of cement, plasticizer, etc.) and on the applied curing method. Afther 28 days the system of HPC shows a com- 
pressive strength of $137.2 / 149.6 \mathrm{MPa}$ (cured in water/air), and after 180 days it reaches $154.9 / 168.3 \mathrm{MPa}$ (cured 28 days in water/air) [3]. Samples of UHPC stored for 48 hours in hot steam at $90{ }^{\circ} \mathrm{C}$ and $95 \%$ relative humidity are characterized by a $19 \%$ increase of modulus of elasticity (52.7 GPa) compared to laboratory-cured samples 4. The maximum flexural strength of ultra-high-performance fibre-reinforced concrete (UHPFRC) increases by $11 \%$ after being exposed for 72 hours to a temperature of $90{ }^{\circ} \mathrm{C}$ in a humid environment [5]. Vogel et al. [6] describe the time development of compressive strength and flexural strength of CM and FRCM for textile concrete production cured under laboratory conditions. At the age of one day compressive strength reached 49.7/27.5 MPa (CM/FRCM), while after 28 days it reached 114.0/108.5 MPa (CM/FRCM). A rapid increase of mechanical properties during the first 7 days characterizes cement composites classified as HPC or UHPC (containing basalt aggregate and CEM I 42,5 R) [7. In this work, Reiterman et al. described the time dependence of compressive strength from an early age until 180 days.

Hydrothermal curing in an autoclave device (with a combination of high pressure and temperature, under the simultaneous effect of steam) provides a sophisticated possibility to achieve high final strength in a short time after the first contact between water and cement (approximately 2 days). A major effect of this solution is the formation of a denser microstructure with the formation of a calcium silicate hydrate (C$\mathrm{S}-\mathrm{H})$ phase, which results in higher mechanical properties [8. The texture of autoclaved UHPC shows a homogeneous, dense cement paste which consists of close networked crystal fibres with a length up to one micrometre in a specimen cured at $200{ }^{\circ} \mathrm{C}$ and 15 bar [9. A magnificent increase of compressive and flexural strength was achieved on high-performance concrete with addition of reactive powder concrete (RPC). Compared to a reference mixture $(80 \mathrm{MPa})$ the combination of $2 \mathrm{MPa}$ and $210^{\circ} \mathrm{C}$ resulted in compressive strength of $202 \mathrm{MPa}$ after 8 hours of curing [9]. In addition, different behaviour of matrix for TRC in terms of special curing conditions can be expected at higher-strength characteristics.

The evaluation of the hydrothermal curing process took into account basic material and mechanical properties (bulk density, flexural strength, compressive strength and dynamic modulus of elasticity). During the experimental program specimens with dimensions of $40 \times 40 \times 160 \mathrm{~mm}^{3}$ were made from high-strength cement matrix and steel fibre-reinforced cement matrix and various mechanical tests were performed.

\section{Hydrothermal CURING}

\subsection{CURING BEFORE HYDROTHERMAL PROCESS}

Samples from CM and FRCM with dimensions of $40 \times 40 \times 160 \mathrm{~mm}^{3}$ were produced under laboratory

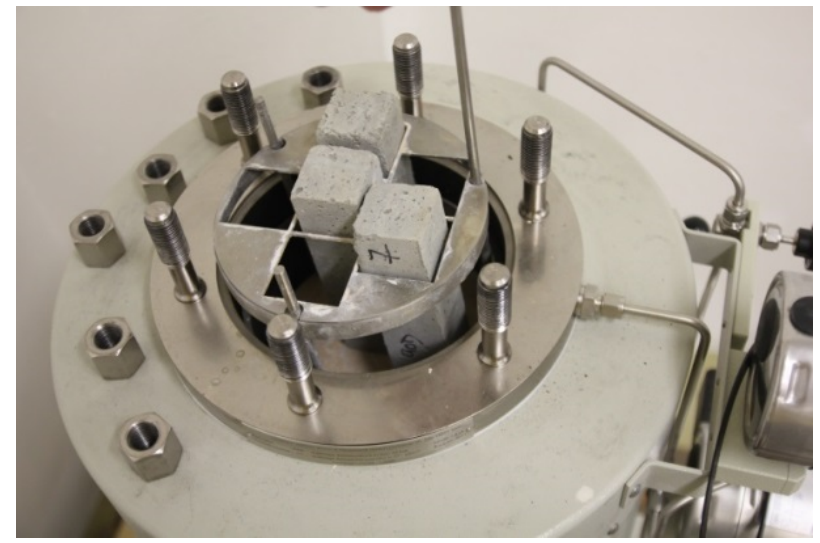

Figure 1. Pressure vessel and steel holder with specimens.

conditions. Fresh mixtures were put into steel forms and their surface was covered by impermeable foil to avoid evaporation of technological water. The specimens remained in steel forms under laboratory conditions $\left(20^{\circ} \mathrm{C}\right.$, at a relative humidity of $\left.50 \%\right)$ until the time when the hydrothermal process took place. The hydrothermal process took place at various ages of the fresh samples $(12,15,18,21$ and 24 hours).

\subsection{Hydrothermal process}

"Hydrothermal curing condition" refers to the combination of high pressure (0.1-0.8 MPa) and temperature $\left(100-250^{\circ} \mathrm{C}\right)$ in a steam-saturated environment applied at an early stage of thehydration process. These conditions can be achieved in the autoclave device. The arrangement of a high pressure vessel's enables the current treatment of six samples with the following dimensions $40 \times 40 \times 160 \mathrm{~mm}^{3}$. The process itself consists of several phases: measurement of the dimensions and weight and placement of the samples into a stainless steel stand; relocation of the specimens into the pressure chamber (Figure 1) of the autoclave, along with approximately 1.0 litre of water; placement of the cover onto the pressure vessel and locking by nuts. The second phase of the autoclaving process involves setting the required pressure at the set-point pressure gauge, opening the pressure-release valve, and turning on the heating units. After reaching $100{ }^{\circ} \mathrm{C}$, the steam started to escape from the pipe of the pressure-release valve, which had to be closed. The pressure and temperature in the high-pressure chamber started to rise up due to the closed pressurerelease valve until the required values were reached (in this experimental program, there were $135^{\circ} \mathrm{C}$ and $0.3 \mathrm{MPa} ; 150^{\circ} \mathrm{C}$ and $0.45 \mathrm{MPa} ; 165^{\circ} \mathrm{C}$ and $0.60 \mathrm{MPa}$ ). After four hours the heating units were switched off while the cooling fan was switched on. During the cooling phase, the pressure and temperature gradually decrease to $100^{\circ} \mathrm{C}$ and $0.1 \mathrm{MPa}$, when the precision pressure-release valve opens and from this moment the pressure in pressure vessel is the same as atmospheric pressure. The pressure vessel was opened and the spec- 
Analysis of Mechanical Properties of Hydrothermally Cured High Strength Matrix for Textile Reinforced VOL. 55 NO. $5 / 2015$

Concrete

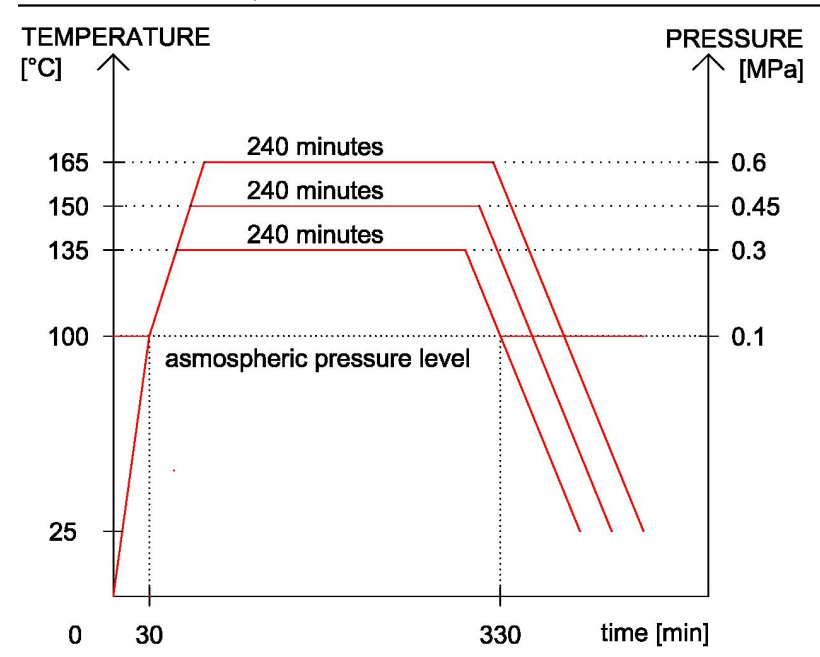

Figure 2. Pressure and temperature curves of hydrothermal processes.

imens were removed when the temperature decreased to laboratory conditions (approximately $20^{\circ} \mathrm{C}$ ). At the end of this process, all the samples reach the final properties and are suitable for expedition (in the case of real production) or for testing of material properties (in laboratory practice). Figure 2 schematically shows all three hydrothermal processes (characterized by different boundary conditions - temperature and pressure). We can see the pressure curve and temperature curve depending on time. The pressure starts to rise up when the temperature exceeds $100{ }^{\circ} \mathrm{C}$ and the pressure-release valve is closed.

\section{Composition}

The maximum grain size of $2 \mathrm{~mm}$ characterizes the cement matrix for TRC production in general; the designed mixture used for this experiment has a maximum grain size of $1.2 \mathrm{~mm}$. Due to the excellent workability of the fresh mixture, the water to binder ratio achieves a slightly higher value $(0.29$ or even 0.31$)$ than in the case of UHPC or UHPFRC (0.19) [10] or than in the case of high-performance cement composite for high temperature application (0.25) [11]. The composition of the mixtures used can be seen in Table 1 . The slightly higher value of water to binder ratio of FRCM is due to steel fibres dosage. Applied CEM I 42.5 R cement replaces the commonly used CEM $52.5 \mathrm{R}$ in the UHPC category $[12,13]$. The philosophy of manufacture is in compliance with the technology of UHPC productions. In short, the homogenization of silica sand and silica fume takes place for 5 minutes; the process of mixing continues with the addition of silica powder and cement and homogenization for next 5 minutes. The water and the plasticizer are added in the same time and the process of mixing the cement matrix ends after 5 minutes. In the case of fibre-reinforced cement matrix the gradual addition of full fibres dosage and their even mixing takes the last 5 minutes.

\begin{tabular}{lcc}
\hline Component & $\begin{array}{c}\text { CM } \\
{\left[\mathrm{kg} / \mathrm{m}^{3}\right]}\end{array}$ & $\begin{array}{c}\text { FRCM } \\
{\left[\mathrm{kg} / \mathrm{m}^{3}\right]}\end{array}$ \\
\hline CEM I 42.5 R cement & 680 & 680 \\
Silica fume & 129 & 129 \\
Silica sand 0.1/0.6 & 326 & 326 \\
Silica sand 0.3/0.8 & 340 & 340 \\
Silica sand 0.6/1.2 & 258 & 258 \\
Silica powder & 326 & 326 \\
SVC 1035superplasticizer & 6.8 & 7.5 \\
Potable water & 238 & 252 \\
Steel fibres 0.14 $\times 13 \mathrm{~mm}$ & - & 102 \\
Water-binder & 0.29 & 0.31 \\
\hline
\end{tabular}

TABle 1. Composition of the mixture used.

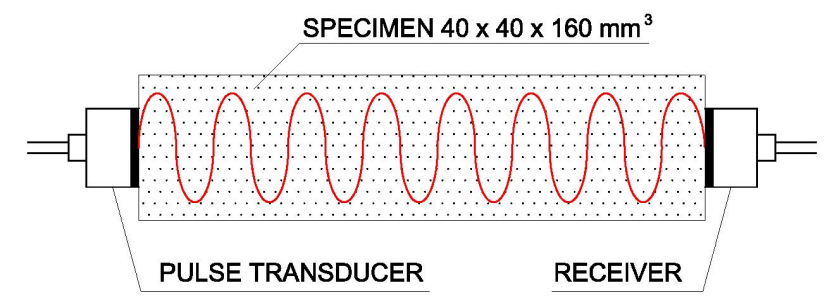

Figure 3. Principle of ultrasonic testing.

\section{InVESTIGATED PROPERTIES}

Evaluation of the optimal age of cement matrix or fibre-reinforced cement matrix and of the conditions in the autoclave device (temperature and pressure) took place with the help of non-destructive measurements of dynamic modulus $\left(E_{c u}\right)$, calculation of bulk density $(\varrho)$ and destructive measuring of the following mechanical parameters: compressive strength $\left(f_{c m}\right)$ and flexural strength $\left(f_{t m}\right)$. All properties were measured on three samples and the final value is an average, except for the compressive strength value (average of six values - fragments from bending tests).

\subsection{Dynamic modulus of Elasticity}

Non-destructive methods find their significant role in civil engineering, material science, diagnostics of structures, and descriptions of gradual changes in materials due to temperature, moisture and dynamic loading $[14,15,16]$. A Proceq PunditLab+ ultrasonic velocity test instrument has been used to determine ultrasound speed vL by $54 \mathrm{kHz}$ pulse transducer. Ultrasonic direct transmission is the most frequently used arrangement where pulse amplitude reaching the receiving transducer is the highest. The one-dimensional adjustment requires the position of pulse transducer and the receiver to be positioned on the opposite sides of the $40 \times 40 \times 160 \mathrm{~mm} 3$ specimen, and to be pointed directly at each other (Figure 3). The following equation determines the values of the dynamic modulus of elasticity (bulk density was calculated from dimension and weight; pulse velocity measured by Proceq PunditLab + and the characteristics of environment were equal to one, because of the one dimensional 


\begin{tabular}{|c|c|c|c|c|c|c|c|c|c|}
\hline \multirow[t]{2}{*}{ Conditions } & \multirow[t]{2}{*}{ Age } & \multicolumn{2}{|c|}{$f_{c m}[\mathrm{MPa}]$} & \multicolumn{2}{|c|}{$f_{t m}[\mathrm{MPa}]$} & \multicolumn{2}{|c|}{$E_{c u}[\mathrm{GPa}]$} & \multicolumn{2}{|c|}{$\varrho\left[\mathrm{kg} \mathrm{m}^{-3}\right]$} \\
\hline & & $\mathrm{CM}$ & FRCM & CM & FRCM & CM & $\overline{\text { FRCM }}$ & $\mathrm{CM}$ & FRCM \\
\hline \multirow[t]{5}{*}{$0.30 \mathrm{MPa} 135^{\circ} \mathrm{C}$} & $12 \mathrm{~h}$ & 83.5 & 94.1 & 13.3 & 25.2 & 38.9 & 37.4 & 2150 & 2250 \\
\hline & $15 \mathrm{~h}$ & 117.5 & 133.8 & 13.0 & 23.5 & 41.7 & 41.6 & 2190 & 2285 \\
\hline & $18 \mathrm{~h}$ & 113.5 & 145.2 & 15.5 & 34.6 & 42.0 & 41.8 & 2200 & 2300 \\
\hline & $21 \mathrm{~h}$ & 116.9 & 144.0 & 10.0 & 28.6 & 41.9 & 41.7 & 2190 & 2305 \\
\hline & $24 \mathrm{~h}$ & 120.4 & 154.7 & 16.9 & 39.8 & 45.0 & 43.1 & 2240 & 2320 \\
\hline \multirow[t]{5}{*}{$0.45 \mathrm{MPa} 150^{\circ} \mathrm{C}$} & $12 \mathrm{~h}$ & 58.3 & 63.4 & 9.5 & 24.0 & 30.2 & 29.2 & 2165 & 2295 \\
\hline & $15 \mathrm{~h}$ & 102.4 & 106.7 & 16.9 & 29.6 & 43.7 & 39.7 & 2180 & 2250 \\
\hline & $18 \mathrm{~h}$ & 122.5 & 163 & 17.2 & 40.0 & 41.2 & 43.3 & 2140 & 2310 \\
\hline & $21 \mathrm{~h}$ & 118.8 & 175.3 & 19.2 & 39.2 & 44.7 & 45.2 & 2220 & 2320 \\
\hline & $24 \mathrm{~h}$ & 125.5 & 171.9 & 15.6 & 46.0 & 46.1 & 45.6 & 2225 & 2260 \\
\hline \multirow[t]{5}{*}{$0.60 \mathrm{MPa} 165^{\circ} \mathrm{C}$} & $12 \mathrm{~h}$ & 30.1 & 48.7 & 4.1 & 11.4 & 13.9 & 20.1 & 2200 & 2260 \\
\hline & $15 \mathrm{~h}$ & 84.2 & 70.7 & 12.0 & 23.3 & 38.2 & 32.2 & 2190 & 2250 \\
\hline & $18 \mathrm{~h}$ & 123.0 & 150.1 & 16.3 & 38.4 & 44.7 & 48.9 & 2190 & 2300 \\
\hline & $21 \mathrm{~h}$ & 134.3 & 177.5 & 25.9 & 48.4 & 44.9 & 45.5 & 2225 & 2320 \\
\hline & $24 \mathrm{~h}$ & 127.3 & 169.2 & 16.0 & 52.3 & 45.3 & 46.1 & 2190 & 2315 \\
\hline Reference: 1 day & & 49.7 & 27.5 & 9.4 & 23.9 & 23.1 & 22.1 & 2240 & 2270 \\
\hline Reference: 28 days & & 114.6 & 108.5 & 15.7 & 34.1 & 34.2 & 34.3 & 2260 & 2230 \\
\hline
\end{tabular}

TABLE 2. Summary of performed experiments - measured data.

arrangement):

$$
E_{c u}=\frac{\varrho v_{L}^{2}}{k^{2}}
$$

where $E_{c u}$ is the dynamic modulus of elasticity [MPa]; $\varrho$ is the bulk density of measured material $\left[\mathrm{kg} \mathrm{m}^{3}\right] ; v_{L}$ is the pulse velocity of ultrasonic waves $\left[\mathrm{ms}^{-1}\right] ; k$ is the characteristics of the environment [-] [17].

\subsection{MECHANiCAL PROPERTIES}

All investigated parameters were determined on prismatic specimens which had the following dimensions: $40 \times 40 \times 160 \mathrm{~mm}^{3}$. The measurement of flexural strength $f_{t m}$ was organized as a three-point bending test with supports at a distance of $100 \mathrm{~mm}$ according to [18, and was calculated with the help of the maximum reached force. An MTS 100 universal loading machine was used for this testing, and the test was controlled by the increase of deformation $(1.0 \mathrm{~mm} / \mathrm{min})$. The compressive strength test $f_{c m}$ was performed on two fragments left after the bending test with the help of the EU 40 machine with a maximum force of $400 \mathrm{kN}$. The area under compressive load $\left(40 \times 40 \mathrm{~mm}^{2}\right)$ was demarcated by the Matest loading-device put to EU 40. This arrangement fully complies with the requirements for refractory cement composites, HPC, UHPC, UHPFRC testing $[11,13]$.

\section{Results}

First, it is necessary to say that all testing of the mechanical properties of the hydrothermally cured specimens was performed on the day following the hydrothermal curing process (the final properties are achieved at the end of the hydrothermal curing process in an autoclave device). The values measured for the samples cured under laboratory conditions and tested after 1 day and after 28 days (which is the time when the strength parameters of cement composites are investigated in practice) are listed for better comparison. Table 2 shows the results of all measurements (compressive strength, flexural strength, dynamic modulus of elasticity and bulk density) performed during the experimental program. The values for all these parameters of the 1-day and 28-day-old samples are shown for comparison with the autoclaved samples. Three different sets of conditions $\left(0.3 \mathrm{MPa}\right.$ and $135^{\circ} \mathrm{C} ; 0.45 \mathrm{MPa}$ and $150^{\circ} \mathrm{C}$; $0.60 \mathrm{MPa}$ and $165^{\circ} \mathrm{C}$ ), together with the different ages at which the samples were hydrothermally cured, are listed.

The dependence of the compressive strength $\left(f_{\mathrm{cm}}\right)$ of CM (Figure 4) and FRCM (Figure 5) on pressure and on temperature is expressed in graphs for better illustration. Figures 6 and 7 show the values of the flexural strength $\left(f_{t m}\right)$ of CM and FRCM after different hydrothermal conditions and ages of the samples. Especially in Figures 4 and 5 , we can see the influence of rising pressure on the compressive strength applied to specimens of various ages. The red line in each graph defines the boundary of each mechanical property measured on the reference samples at 28 days. This will help achieve better orientation, where all values of hydrothermal cured samples up to the line reach higher values of mechanical properties.

\section{Conclusions And discussion}

Based on the performed experiments, on the summarization of the results, and on the graphical evaluation, we can find several dependencies and draw several con- 


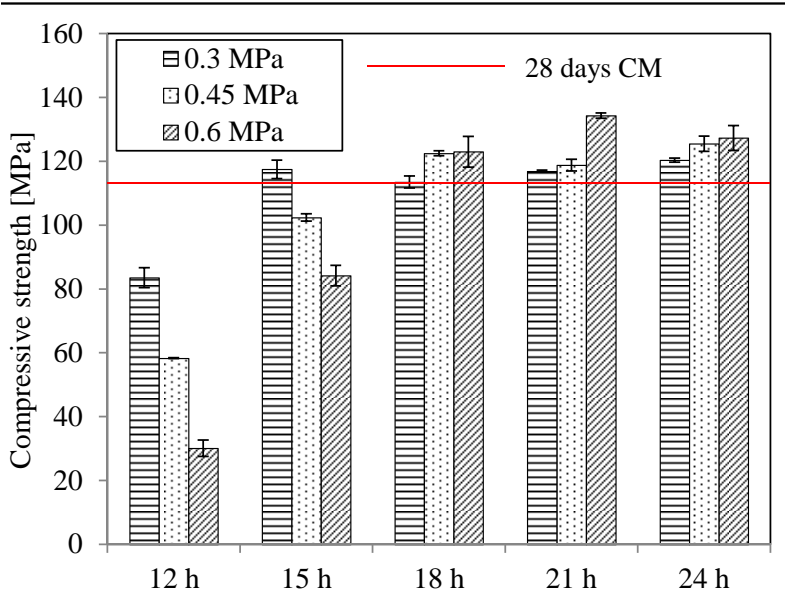

FiguRE 4. Average values of compressive strength $f_{c m}$ of CM after curing under different conditions.

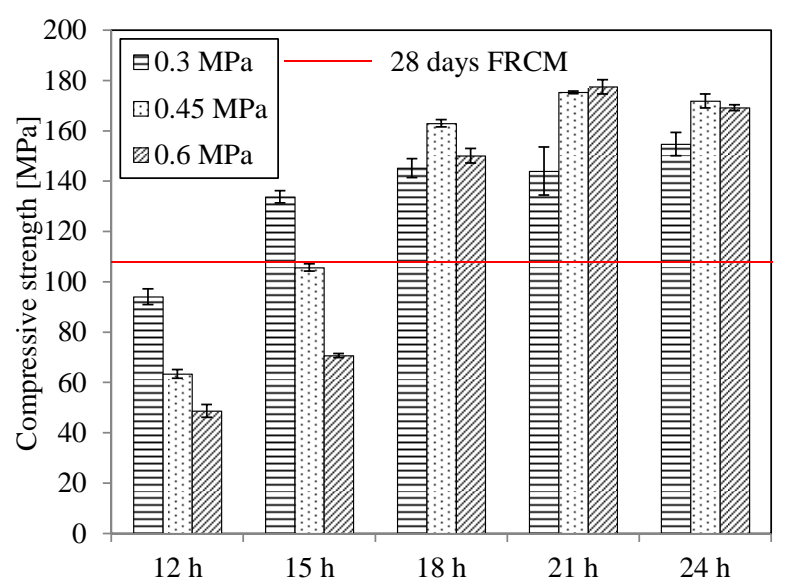

Figure 5. Average values of compressive strength $f_{c m}$ of FRCM after curing under different conditions.

clusions. The compressive strength, flexural strength, and the dynamic modulus of elasticity were measured on 90 specimens in total, which were tested after being cured under various conditions in an autoclave device $\left(135^{\circ} \mathrm{C}\right.$ and $0.3 \mathrm{MPa} ; 150^{\circ} \mathrm{C}$ and $0.45 \mathrm{MPa}$; $165^{\circ} \mathrm{C}$ and $\left.0.6 \mathrm{MPa}\right)$. According to the outcomes from the performed experimental program, the following conclusions can be presented:

(1.) The compressive strength $\left(f_{c m}\right)$ of the cement matrix does not increase as rapidly as that of the fibre-reinforced cement matrix. The maximum increase achieved for CM is $14.5 \%$ in comparison with samples tested at 28 days. The increase observed for FRCM is $38.9 \%$. We can observe the maximum compressive strength on samples hydrothermally cured at the ages of 21 hours or 24 hours. Based on the values of flexural strength $\left(f_{t m}\right)$, we can confirm the assumption of theoretical research that the positive influence of hydrothermal curing lies in tensile characteristics. An increase of $34.7 \%$ characterizes the flexural strength of FRCM hydrothermally cured at 24 hours under the following conditions: $165^{\circ} \mathrm{C}$ and $0.6 \mathrm{MPa}$.

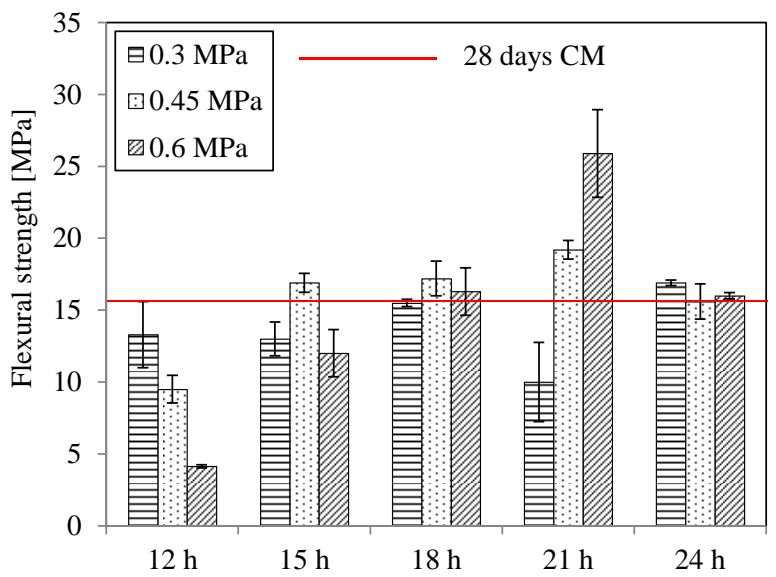

Figure 6 . Average values of flexural strength $f_{t m}$ of $\mathrm{CM}$ after curing under different conditions.

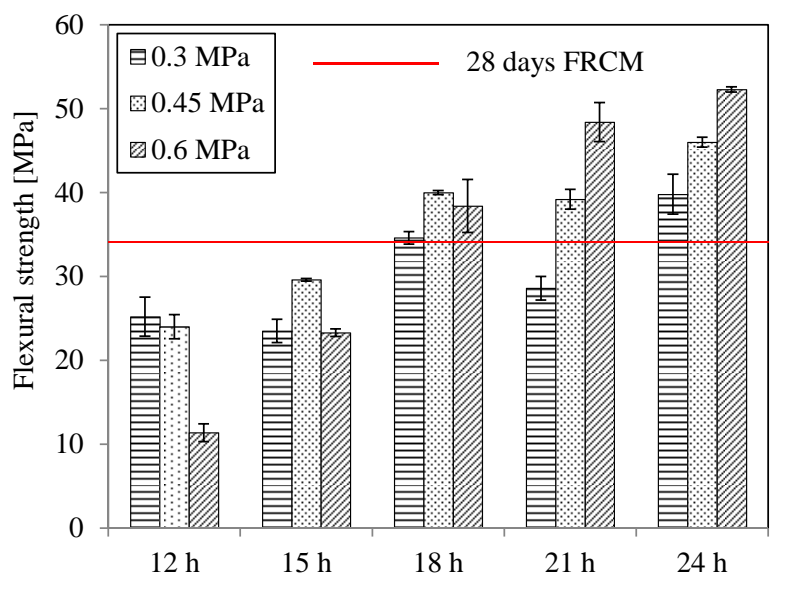

Figure 7 . Average values of flexural strength $f_{t m}$ of FRCM after curing under different conditions.

(2.) Application of pressure higher than 0.60 MPa at a temperature higher than $160^{\circ} \mathrm{C}$ will probably result in even better mechanical characteristics, but to the detriment of economy of production. Higher pressure means more expensive production (costs for energy) and the hydrothermal process has to be applied to older samples (due to the initial strength being sufficient to resist the high pressure).

(3.) Increasing the temperature and pressure in an autoclave leads to lower values of mechanical properties of younger samples (typically 12 and 15 hours). The samples at this age are not strong enough to resist the pressure, which will result in micro-cracks and decreased strength. Application of lower pressure $-0.3 \mathrm{MPa}$ - at the age of 12 hours leads to values of compressive strength three times higher than 0.6 MPa. The hydrothermal condition takes effect especially at the ages of 21 and 24 hours, when the initial strength parameters are able to resist inner destruction due to high pressure.

(4.) Increasing mechanical parameters are accompanied by growth of the bulk density and dynamic modulus of elasticity. The bulk density growth is as- 
sociated with denser microstructure and hydration products due to hydrothermal curing conditions.

We can conclude from the performed experiments that hydrothermal curing has a great potential for textile reinforced concrete production (especially of façade panels, load-bearing elements and other precast structure parts). The most suitable combination of boundary conditions (pressure and temperature) and final mechanical properties always takes into account technological and especially economical aspects. Denser microstructure, developed in autoclaved cured specimens, is connected with the presumed lower permeability for liquids and gases. Higher durability and long-term properties are connected with low permeability. The financial costs of hydrothermally cured samples have to be compensated by final mechanical characteristics. Therefore, the hydrothermally cured elements are supposed to be used in extreme extensive places, with high requirements in terms of durability and resistance to extreme static or dynamic load.

\section{ACKNOWLEDGEMENTS}

This research work was supported by the Czech Science Foundation under project GAP 105/12/G059 "Cumulative time dependent processes in building materials and structures". The authors gratefully acknowledge the assistance given by the technical staff of the Experimental Centre department of the Faculty of Civil Engineering, CTU in Prague.

\section{REFERENCES}

[1] Brückner, A., Ortlepp, R., Curbach, M.: Textile Reinforced Concrete for Strengthening in Bending and Shear, Materials and Structures (2006), pp. 741-748. DOI:10.1617/s11527-005-9027-2

[2] Schladitz, F., Frenzel, M., Ehlig, D., Curbach, M.: Bending Load Capacity of Reinforced Concrete Slabs Strengthened with Textile Reinforced Concrete, Engineering Structures 40, (2012), pp. 317-326. DOI:10.1016/j.engstruct.2012.02.029

[3] Holčapek, O., Vogel, F., Vavřiník, T., Keppert, M.: Time Progress of Compressive Strength of High Performance Concrete, Applied Mechanics and Materials, Vol. 486, (2014), pp. 167-172. DOI:10.4028/www.scientific.net/AMM.486.167

[4] Graybeal, B. A.: Compressive Behavior of Ultra-High-Performance Fiber-Reinforced Concrete, ACI Materials Journal (2007), Vol. 104, pp. 146-152. DOI:10.14359/18577

[5] Hong, K. N., Kang, S. T., Kim, S. W., Park, J. J., Han, S. H.: Material Properties of Air-cured Ultra-high-performance Steel-fiber-reinforced Concrete at Early Ages, International Journal of the Physical Sciences, 5 (2010). ISSN-1992-1950

[6] Vogel, F., Holčapek, O., Jogl, M., Kolář, K., Konvalinka, P.: Development of Mechanical Properties of Steel Fibers Reinforced High Strength Concrete,
Advanced Material Research, Vol. 1077 (2015), pp. 113-117. DOI:10.4028/www.scientific.net/AMR.1077.113

[7] Reiterman, P., Jogl, M., Bäumelt, V., Seifrt, J.: Development and Mix Design of HPC and UHPFRC, Advanced Material Research, Vol. 982 (2014), pp. 130-135. DOI:10.4028/www.scientific.net/AMR.982.130

[8] Lehmann, C., Fontana, P., Müller, U.: Evolution of Phases and Micro Structure in Hydrothermally Cured Ultra-High Performance Concrete (UHPC),

Nanotechnology in Construction: Proceeding of the NICOM3, ISBN 978-3-642-00979-2, (2009), pp. 287-293. DOI:10.1007/978-3-642-00980-8_38

[9] Yazici, H., Deniz, E., Baradan, B.: The effect of autoclave pressure, temperature and duration time on mechanical properties of reactive powder concrete, Construction and Building Materials 42, (2013), pp. 53-63. DOI:10.1016/j.conbuildmat.2013.01.003

[10] Sovják, R., Vogel, F., Beckmann, B.: Triaxial Compressive Strength of Ultra High Performance Concrete, Acta Polytechnica, 53, 2013, doi:10.14311/AP.2013.53.0901

[11] Holčapek, O., Reiterman, P., Konvalinka, P.: Experimental Analysis of Hydrothermal Curing Influence on Properties of Fiber-Cement Composite, Applied Mechanics and Materials, Vol. 732 (2015), pp. 55-58. DOI:10.4028/www.scientific.net/AMM.732.55

[12] Sovják, R., Vavřiník, T., Zatloukal, J., Máca, P., Mičunek, T., Frydrýn, M.: Resistance of slim UHPFRC targets to projectile impact using in-service bullets, International Journal of Impact Engineering (2015), Vol. 76, pp. 166-177. doi:10.1016/j.ijimpeng.2014.10.002

[13] Reiterman, P., Holčapek, O., Polozhiy, K., Konvalinka, P.: Fracture properties of cement pastes modified by fine ground ceramic powder, Advanced Material Research, Vol 1054 (2014), pp. 182-187, DOI:10.4028/www.scientific.net/AMR.1054.182

[14] Holčapek, O., Reiterman, P., Konvalinka, P.: Fracture characteristics of refractory composites containing metakaolin and ceramic fibers, Advances in Mechanical Engineering, vol. 7, no.3 (2015), pp. 1-13, DOI:10.1177/1687814015573619

[15] Holčapek, O., Reiterman, P., Jogl, M., Konvalinka, P.: Destructive and Non-destructive Testing of High Temperature Influence on Refractory Fiber Composite, Advanced Materials Research, Vol. 982 (2014), pp.145148. DOI:10.4028/www.scientific.net/AMR.982.145

[16] Pavlů, T., Šefflová, M.: The Static and The Dynamic Modulus of Elasticity of Recycled Aggregate Concrete, Advanced Material Research, Vol. 1054 (2014), pp. 221-226. DOI:10.4028/www.scientific.net/AMR.1054.221

[17] CSN EN 12 504-4: Testing of concrete - Part 4: Determination of ultrasonic pulse velocity (2005).

[18] Czech Standard CSN EN 196-1: Methods of testing cement - Part 1: Determination of strength (2005). 